\title{
Feasibility Study of tabata Training in the Reform of Physical Education Teaching in Colleges and Universities
}

\author{
Yongjun $\mathrm{Xiao}^{1}$ \\ ${ }^{1}$ Institute of Technology, East China Jiaotong University, Nanchang, Jiangxi, 330100, China
}

\begin{abstract}
The arrival of Internet technology makes people communicate with the outside world more frequently and conveniently, but it is also because of the high efficiency and convenience of Internet technology that people chat, party, shopping and other activities on the line become more and more frequent. On the contrary, people offline exercise, travel, face-to-face communication and other activities are less and less. In recent years, college students in our country have shown the phenomena of lack of physical ability, decrease of exercise quantity and decrease of physical quality, so it is urgent to reform physical education teaching in colleges and universities. Based on the analysis of the predicament of physical education teaching in colleges and universities, this paper introduces the tabata training method in physical education teaching with high intensity intermittent training method as the focus, so as to realize the reform and development of college education and teaching. It will further improve the physical quality and health of college students.
\end{abstract}

\section{Introduction}

In 2018, the Ministry of Education of our country formally promulgated the National Student system Health Standard, which emphasizes that all schools should take improving students' sports skills and physique as the key work to make students develop good exercise habits and establish healthy sports consciousness. As the successor of socialist cause, college students should not only have solid professional knowledge, but also have good physical quality. However, in recent years, due to less exercise time, limited sports venues, improper sports methods and other factors, the physical quality of college students obviously declines, most college students are in a state of

sub-health. The purpose of education is to realize the all-round development of human morality, intelligence, body, beauty and labor, so the importance of physical education can be imagined.

\section{Scientific Connotation Of Tabata Training Method}

Intermittent training is a combination of high intensity training and short rest in a short period of time training modes to achieve the purpose of developing physical fitness. Intermittent training has the characteristics of time-saving and efficient training. There are three common types:

High intensity intermittent training

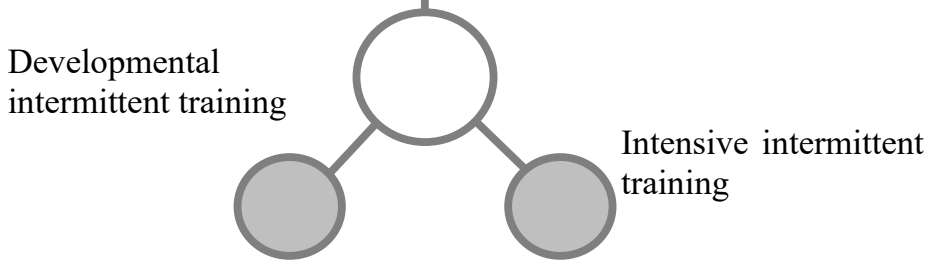

Figure1: Common Types Of In Termittent Training

High intensity intermittent training is considered to be the most effective and widely used training method so far [1]. It is a kind of training mode with high intensity, short time and repeated times close to the maximum oxygen uptake or exceeding the intensity of anaerobic threshold. The influencing factors include exercise mode, intensity, number of times, time, number of exercise groups, intermittent rest intensity and so on. 
tabata training method is a kind of high intensity intermittent training method, its motion intensity is between $90 \%$ and $100 \%$ HRmax, take $20 \mathrm{~s}$ work 10 batches as a group, total eight groups, often $4 \mathrm{~min}$, Therefore, the tabata training method has the remarkable characteristics of high intensity and short time.

\subsection{Effects of tabata training on aerobic and anaerobic capacity}

The results showed that the aerobic ability of the endurance training group was significantly improved, but the anaerobic function ability was not VO2max. Both aerobic and anaerobic working ability of tabata training group were significantly enhanced.

\subsection{Effects of tabata Training on Sugar Metabolism}

The researchers used to compare two groups of rats: the first group was an aerobic training group (45 minutes interval every 3 hours, (6 hours); Group 2 was tabata training group (14\% deadweight, Total exercise (14 groups), After 2,6, and 18 hours, the researchers observed protein levels in the PGC-1 $\alpha$ of skeletal muscle in rats, Results The protein content of skeletal muscle PGC- $1 \alpha$ increased by $84 \%, 95 \%$ and $67 \%$ after 2,6 and 18 hours in the second training group.

\subsection{Effects of tabata training on chronic diseases}

The researchers tested mice with abnormal glandular fossa lesions (ACF) caused by dimethylhydrazine and trained them at a load of $16 \%$ of their. After 4 weeks of tabata training, the ACF number of mice trained was significantly smaller than that of mice without tabata training. Thus, tabata training has a certain effect on inhibiting the development of ACF and can be used to prevent rectal cancer [2].

\section{Current Situation Of Physical Education Teaching In Colleges And Universities}

\subsection{The single type of curriculum can not meet the individual needs of students}

Because of the limited resources and teachers in colleges and universities, most of the teaching items in physical education courses in colleges and universities are characterized by homogeneity, such as basketball, volleyball, football, and tennis and golf. Even if the sports offered in different semesters are different, they can not meet the students' individualized and diversified learning needs, such as volleyball, seemingly simple ball games, some girls learn very easily, while some perform very hard. However, because this course is a compulsory course, students have no right to choose, so the interest is naturally low and the learning effect is not expected. In addition, many physical education teachers mainly focus on skill guidance, but ignore the explanation of theoretical knowledge, so that students' physical education literacy is insufficient, many students do not understand why to learn and how to do a good physical education.

\subsection{The theory teaching is insufficient, the physical ability class curriculum is obviously scarce.}

Many PE teachers think that the purpose of physical education is to pass the final exam. At present, the proportion of theoretical teaching in physical education in colleges and universities is very small, and most colleges and universities have only $6 \%$ to $10 \%$ of the courses in physical education theory. Because the theoretical knowledge of physical education has not formed a complete and independent knowledge system, the scientific and interesting physical education theory course is seriously missing[3]. In addition, students do not know the purpose of the course learning clearly, resulting in the class is more perfunctory, casual, learning results are naturally unsatisfactory. The aim of physical education courses should be to improve students' physical fitness, strengthen their physique and form a good sense of health.

\subsection{Sports facilities for extracurricular sports are severely inadequate}

It is found that the teaching and extracurricular sports facilities in colleges and universities in China are obviously insufficient. Although some colleges and universities have relevant hardware facilities, due to curriculum conflicts or management problems, the actual available extracurricular sports venues and facilities are insufficient. For example, the sports venues in colleges and universities, because the sports law stipulates that the sports facilities of colleges and universities belong to the community, the implication is that the sports venues of colleges and universities should also be open to the society, which directly affects the students' use opportunities and the effect of physical education teaching.

\section{Analysis On The Appropriateness Of Tabata Training In College Physical Education Teaching}

\section{1 tabata training fits students' exercise load}

Although there are many problems in physical education teaching in colleges and universities at present, the physical training mainly shows that the number of exercises, the number of groups, the time and the intensity of the students can not meet the needs of the students' physical development. At present, the density of physical education teaching in colleges and universities is less than 40, and the teaching density of improving 
students' physical education literacy and truly feeling the charm of physical education should be 75 . In other words, the density of physical education teaching in colleges and universities can not make students develop a correct understanding of physical education. The study shows that when the heart rate reaches 140 beats / min to 160 beats / min, students can feel the fun of exercise, while most students in physical education class do not sweat and their faces are not red and breathless. From this, it can be seen that in the actual teaching of physical education, the students' sports load is far from reaching the standard, and the training characteristics of high intensity and density of tabata training can well meet the needs of students' physical development.

\section{2 tabata training to meet the needs of physical education reform}

In the new period, China has put forward higher requirements for the goal of talent training. With the tilt of national policy to physical education, the health of students has risen to the national development strategy again, so it is urgent to deepen the reform of health curriculum and physical education. In the requirements of the new curriculum reform, it is clearly proposed that after the physical education teachers have completed the teaching tasks of certain class hours, the students' health and physical fitness must reach a certain level and grade, and the teachers should test the students' physical education learning results through the quantitative standards[4]. After the introduction of physical education tabata training, it can not only meet the requirements of the new curriculum reform, but also help students to meet the evaluation standard of academic quality as far as possible, and finally improve the students' physical fitness.

\section{3 tabata training can make up for the shortage of teaching resources}

At present, the contradiction between the expansion of college enrollment and the lack of physical education teaching resources is deepening day by day. Physical education teaching in colleges and universities is difficult to meet the diversified growth needs of students. The concrete manifestations are: insufficient professional level of physical education teachers, incomplete facilities of stadiums and gymnasiums, unreasonable setting of theoretical and practical courses, and uneven distribution of teaching resources, which seriously hinder the realization of teaching progress and teaching objectives. By introducing tabata training method, colleges and universities can effectively alleviate the problems caused by the shortage of teaching resources. On the one hand, the tabata training method does not require teachers' professional level and professional ability, so long as teachers have certain executive ability and organize teaching according to the syllabus, they can complete the task. On the other hand tabata the training method is not high on the site and facilities. Teachers can flexibly arrange the venue according to the actual curriculum content.

\section{Feasibility Analysis Of Tabata Training In College Physical Education Teaching}

\subsection{Feasibility Analysis of tabata Training for Student Athletes}

Usually, athletes receive hard training in order to achieve excellent results in the competition. Therefore, in the daily training, the coach will focus on the training of athletes' special skills, but in fact, the results of the competition are often affected by physical fitness, athletes' psychology, tactics and even the environment, among which the physical influence is particularly obvious. As the more important the competition, the more physical fitness can affect the final results of students, so the physical education teaching for students and athletes in colleges and universities should make full use of the tabata training method while carrying out special skills training for students and athletes. Improve students' aerobic and anaerobic ability and ultimately help students win the competition[5].

\subsection{Feasibility Analysis of tabata Training for Ordinary Students}

After all, athletes only account for a small number of college students, and most of them are ordinary students, so is tabata training still applicable to the physical education of ordinary students? The answer is obviously yes. Since college students, as successors to the socialist cause, must have a strong physique, and then affected by the sharp increase in learning pressure and changes in the external environment, more and more college students are in a state of sub-health. This makes it difficult for college students to adapt to the mission entrusted by the times. As a result, it is necessary to carry out tabata training for ordinary students. In addition, teachers should set up different training items and intensity according to students' different needs, interests, physical condition and learning characteristics in the process of training[6].

\subsection{Feasibility Analysis of tabata Training for Obese Students}

The data from the College Students' Physical Health Test show that obesity and overweight are common among students, and obesity data have been high. Obesity of college students has become an important factor hindering the healthy growth of college students and the effectiveness of physical education teaching. Studies show that tabata training has a significant effect on reducing obesity in college students. Teachers, for example, can use tabata training methods to organize students to carry out "kick-off-around marker-shot" exercises, control the intensity of exercise at 60 V.O2max, set the exercise time to $20 \mathrm{~min}$, and the 
interval time to $1 \mathrm{~min}$.

\section{Conclusion}

At present, there are many problems mentioned above in physical education teaching. Colleges and universities should closely focus on the requirements of new curriculum reform and talent training, and explore the concrete application of tabata training in improving college students' physical fitness. Aiming at the problems in physical education teaching at present, colleges and universities and teachers should start from the practical problems of teaching, promote the organic integration of tabata training and daily physical education teaching, and provide a clear direction for the development of college students and the cultivation of talents in colleges and universities.

\section{Acknowledgment}

This work was supported by The teaching reform project of Institute of Technology, East China Jiaotong University.

Project title: Making analysis on the teaching mode which applied Tabata training skills in public physical education curriculam

Project Code: XJJG2019-11

\section{References}

1. Liu, RD.Cao, C.M. Liu, J.X.Li, Q.(2017)Application and Adaptation Mechanism of High Intensity Intermittent Training $[\mathrm{J}]$. sports science .

2. Li, Y.M.(2015)Effect of High Intensity Intermittent Training on Different Training Population[J].sports science .

3. Gao, B.Cao, J.(2019)Effects of High Intensity Intermittent Training on Physical Fitness[J].Hubei Sports Science and Technology.

4. Hu, Y.Y.(2020)Research on Application of High Intensity Intermittent Training[J].Martial arts research.

5. Duan, Q.Y.(2019)Basic Principle and Practice of High Intensity Intermittent Training[J].Neijiang Technology.

6. Li,J.H.(2019)Effect of Tabata training method on anaerobic power of male taekwondo athletes with special action[D].Beijing Sport University . 